\title{
Absceso del psoas y osteomielitis de la columna lumbar. Caso clínico
}

Psoas abscess and lumbar spine osteomyelitis. Case report

\author{
Dra. Ana M. Silva $a^{a}$ Dr. Lauwence A. Schmalbach. ${ }^{b}$
}

\section{RESUMEN}

El absceso del psoas es una enfermedad infrecuente en niños. Puede tener una presentación clínica inespecífica, ser de inicio insidioso y relacionarse o no con fiebre. El tipo más frecuente en pediatría es primario; sin embargo, en ocasiones, puede ser de origen secundario y asociarse a infecciones graves, como la osteomielitis, por lo que se requiere un alto índice de sospecha para detectarlo y tratarlo oportunamente. Presentamos un caso atípico de absceso del psoas con infiltración del cuerpo vertebral de L2 en un paciente masculino de 14 años previamente sano, sin antecedente de traumatismo ni fiebre al momento del ingreso. Se realizaron una radiografía y una ecografía, pero el diagnóstico se confirmó a través de una resonancia nuclear magnética de columna lumbosacra. Con hemocultivos positivos para Staphylococcus aureus meticilino resistente, completó 2 semanas de tratamiento antibiótico endovenoso y 4 semanas por vía oral con negativización de cultivos y resolvió por completo la sintomatología inicial.

Palabras clave: absceso del psoas, osteomielitis vertebral, dolor de la región lumbar, cojera, fiebre.

\section{ABSTRACT}

Psoas abscess is a common disease in children. It can have a nonspecific clinical presentation, insidious onset and sometimes fever. The most common type in children is the primary one; however, itcan sometimes be of secondary origin and associated with severe infections such as osteomyelitis so a high index of suspicion is required to detect and treat it promptly. We present an unusual case of psoas abscess with infiltration of the vertebral body of L2 in a 14 year old male patient previously healthy with no history of trauma or fever on admission. X-ray and ultrasound were performed but the diagnosis was confirmed by magnetic resonance imaging of the lumbosacral spine. With positive blood cultures for methicillin-resistant Staphylococcus aureus he completed 2 weeks of intravenous antibiotic therapy and 4 weeks of oral antibiotic therapy with blood cultures negativization and resolution of symptoms.

Key words: psoas abscess, spine osteomyelitis, low back pain, limp, fever.

a. Servicio de Pediatría. Hospital Central de Pediatría Dr. Claudio Zin, Malvinas Argentinas, Buenos Aires.

b. Servicio de Ortopedia y Traumatología. Hospital Municipal de Trauma y Emergencias Dr. Federico Abete, Malvinas Argentinas, Buenos Aires.

Correspondencia:

Dra. Ana M. Silva: ana_maria_silva@live.com

Financiamiento: Ninguno.

Conflicto de intereses: Ninguno que declarar.

Recibido: $14-12-2015$

Aceptado: 9-3-2016 http:/ /dx.doi.org/10.5546/aap.2016.e333

\section{INTRODUCCIÓN}

El absceso del psoas es una enfermedad infrecuente en niños. Se desconoce su prevalencia en pediatría. Datos provenientes del Reino Unido estimaron una incidencia del 0,4/100000 habitantes. ${ }^{1}$

Los abscesos pueden clasificarse en primarios, más frecuentes en la edad pediátrica, y secundarios. Actualmente, la mortalidad varía entre el $2,8 \%$ y el $20 \%$, y es de $2,5 \%$ en los abscesos primarios y de $18,9 \%$ en los secundarios. ${ }^{2}$

Son de origen primario cuando no se logra demostrar un foco infeccioso contiguo y se plantea diseminación hematógena o linfática de un organismo en localización distal. El secundario se debe a la expansión directa de procesos infecciosos cercanos al psoas de origen intraabdominal, más frecuentes de vías urinarias y traumatológicos. Las principales patologías asociadas son la enfermedad de Crohn, apendicitis aguda y pielonefritis, aunque también se asocian a infecciones primarias de la columna vertebral, espondilitis anquilosante, tumores primarios de médula espinal, enfermedad de Legg-Calvé-Perthes, entre otros. ${ }^{3}$

Presentamos un caso atípico de absceso del psoas en un niño previamente sano, sin antecedentes de traumatismos ni fiebre, que asoció bacteriemia por Staphylococcus aureus meticilino resistente (SAMR) y osteomielitis de columna lumbar. Recibió un manejo conservador por medio de tratamiento antibiótico oportuno con resolución completa del cuadro y buena evolución en el seguimiento ambulatorio.

\section{CASO CLÍNICO}

Paciente masculino de 14 años que consultó por un cuadro de 1 semana de evolución de dolor lumbar izquierdo irradiado al miembro inferior ipsilateral. Había recibido tratamiento ambulatorio con antiinflamatorio y relajante muscular, sin mejoría. 
Ingresó con dolor, dificultad para la marcha, dolor abdominal difuso, sin fiebre ni antecedente de traumatismo. Se plantearon diagnósticos diferenciales, como abdomen agudo, artritis séptica de cadera y artritis sacroilíaca, que se descartaron por medio de estudios complementarios, además de la evaluación especializada.

El análisis de laboratorio de ingreso reportó leucocitos de $13600 \mathrm{cel} . / \mathrm{mm}^{3}$, con ecografía renal normal y ecografía de partes blandas en la región lumbar que reportó piel y tejido celular subcutáneo de características ecográficas habituales, sin alteraciones musculotendinosas ni colecciones agregadas (Tabla 1).
Se realizó una radiografía de columna lumbosacra sin opacidades en el psoas ni signos de discitis (Figura 1.A). Con una radiografía de pelvis que no evidenció erosiones óseas ni aumento del espacio articular, se interconsultó al Servicio de Traumatología Pediátrica, que desestimó el diagnóstico de artritis séptica y solicitó una resonancia nuclear magnética (RNM) de columna dorsal, que reportó osteomielitis de cuerpo vertebral L2 y absceso del psoas izquierdo (Figura 2).

48 horas después del ingreso, presentó registro febril de $38^{\circ} \mathrm{C}$. Se decidió realizar 2 hemocultivos e iniciar un tratamiento antibiótico endovenoso con clindamicina. El análisis de laboratorio de

TABLA 1. Exámenes complementarios. Tabla de parámetros de laboratorio al ingresar, intratratamiento, al momento del alta hospitalaria y del alta

\begin{tabular}{|c|c|c|c|}
\hline \multicolumn{4}{|c|}{ ANÁLISIS DE LABORATORIO } \\
\hline Ingreso & Intratratamiento & Alta hospitalaria & Alta \\
\hline $\begin{array}{l}\text { Hto.: } 35 \% . \\
\text { Hb.: } 11,3 \mathrm{~g} / \mathrm{dL} . \\
\text { Gb: } 13600 \\
\text { cel./mm }{ }^{3} . \\
\text { Plaq.: } 392000 \\
\text { cel. } / \mathrm{mm}^{3} .\end{array}$ & $\begin{array}{l}\text { Hto.: } 37 \% . \\
\text { Hb.: } 12,1 \mathrm{~g} / \mathrm{dL} . \\
\text { Gb: } 11000 \\
\text { cel. } / \mathrm{mm}^{3} . \\
\text { Plaq.: } 354000 \\
\text { cel. } / \mathrm{mm}^{3} . \\
\end{array}$ & $\begin{array}{l}\text { Hto.: } 33 \% \text {. } \\
\text { Hb.: } 10,6 \mathrm{~g} / \mathrm{dL} \text {. } \\
\text { Gb: } 7600 \mathrm{cel} . / \mathrm{mm}^{3} \text {. } \\
\text { Plaq.: } 348000 \\
\text { cel. } / \mathrm{mm}^{3} .\end{array}$ & $\begin{array}{l}\text { Hto.: } 39 \% \text {. } \\
\text { Hb.: } 12,6 \mathrm{~g} / \mathrm{dL} . \\
\text { Gb: } 7400 \mathrm{cel} . / \mathrm{mm}^{3} \text {. } \\
\text { Plaq.: } 234000 \\
\text { cel. } / \mathrm{mm}^{3} .\end{array}$ \\
\hline & ESD: $80 \mathrm{~mm}$. & ESD: $105 \mathrm{~mm} / \mathrm{h}$. & ESD: $15 \mathrm{~mm} / \mathrm{h}$. \\
\hline & & PCR: 14 mg/L. & PCR: 0,1 mg/L. \\
\hline \multicolumn{4}{|c|}{ ESTUDIOS DE IMAGEN } \\
\hline Ingreso & Intratratamiento & Alta hospitalaria & Alta \\
\hline $\begin{array}{l}\text { - Ecografía } \\
\text { renal: } \\
\text { Sin } \\
\text { particularidades. }\end{array}$ & $\begin{array}{l}\text { - Ecografía } \\
\text { renal: } \\
\text { Sin } \\
\text { particularidades. }\end{array}$ & \multirow{3}{*}{$\begin{array}{l}\text { - Radiografía de } \\
\text { columna } \\
\text { lumbosacra } \\
\text { (frente-perfil- } \\
\text { oblicua): } \\
\text { Sin } \\
\text { particularidades. }\end{array}$} & \multirow{3}{*}{$\begin{array}{l}\text { - Radiografía de } \\
\text { columna } \\
\text { lumbosacra } \\
\text { (frente-perfil- } \\
\text { oblicua): } \\
\text { Sin } \\
\text { particularidades. }\end{array}$} \\
\hline $\begin{array}{l}\text { - Ecografía de } \\
\text { partes blandas } \\
\text { de la región } \\
\text { lumbar: } \\
\text { Sin } \\
\text { particularidades. }\end{array}$ & $\begin{array}{l}\text { - Ecografía de } \\
\text { partes blandas } \\
\text { de la región } \\
\text { lumbar: } \\
\text { Sin } \\
\text { particularidades. }\end{array}$ & & \\
\hline $\begin{array}{l}\text { - Radiografía de } \\
\text { dorso lumbar: } \\
\text { Sin } \\
\text { particularidades. }\end{array}$ & $\begin{array}{l}\text { - Resonancia } \\
\text { nuclear } \\
\text { magnética de } \\
\text { columna dorsal: } \\
\text { Lesión } \\
\text { hiperintensa en el } \\
\text { cuerpo vertebral de } \\
\text { L2; colección de } 13 \\
\text { mm en el músculo } \\
\text { psoas izquierdo. }\end{array}$ & & \\
\hline \multicolumn{4}{|c|}{ CULTIVOS } \\
\hline $\begin{array}{r}\text { (HMC d } \\
\text { Hemocu } \\
(+)(+) \text { Staphylococc } \\
\text { resis }\end{array}$ & $\begin{array}{l}\text { inicio) } \\
\text { tivo } \times 2 \text { : } \\
\text { s aureus meticilino } \\
\text { ente. }\end{array}$ & $\begin{array}{r}\text { (HMC de } \\
\text { Hemocu } \\
(-)(-) \mathrm{Ne}\end{array}$ & $\begin{array}{l}\text { Control) } \\
\text { ivo } \times 2 \text { : } \\
\text { ativos. }\end{array}$ \\
\hline
\end{tabular}

Hto.: hematocrito; Hb.: hemoglobina; Gb: glóbulos blancos; Plaq.: plaquetas; ESD: eritrosedimentación; PCR: proteína C reactiva; HMC: hemocultivo. 
control evidenció leucocitos de $11000 \mathrm{cel} . / \mathrm{mm}^{3}$ y eritrosedimentación de $80 \mathrm{~mm}$. Al cuarto día de internación, persistía con registros febriles aislados y los reportes de los hemocultivos fueron positivos para SAMR, por lo que se asoció vancomicina, con la toma previa de nuevos hemocultivos (Tabla 1).

Recibió 3 días de tratamiento endovenoso con vancomicina hasta tener hemocultivos de control negativos y proteína $C$ reactiva (PCR) en descenso, con lo que se suspendió e inició un esquema antibiótico por vía oral con rifampicina y clindamicina. Permaneció afebril por más de 1 semana, sin dolor, sin limitación para la marcha ni trastorno de tipo motor o sensitivo. Los controles de laboratorio fueron normales y la radiografía de columna lumbosacra, sin signos de lesión en los cuerpos ni discos vertebrales (Figura 1.B), lo que definió su egreso hospitalario.

Durante la internación, el paciente recibió en total 15 días de tratamiento antibiótico endovenoso con clindamicina (30 mg/ $\mathrm{kg} /$ día) asociado a 3 días de vancomicina $(60 \mathrm{mg} / \mathrm{kg} /$ día), definidos por su evolución clínica, hasta la

Figura 1. Seguimiento radiográfico (frente y perfil) de la columna lumbosacra. A) Al ingresar. B) Al momento del alta hospitalaria. C) Al momento del alta.

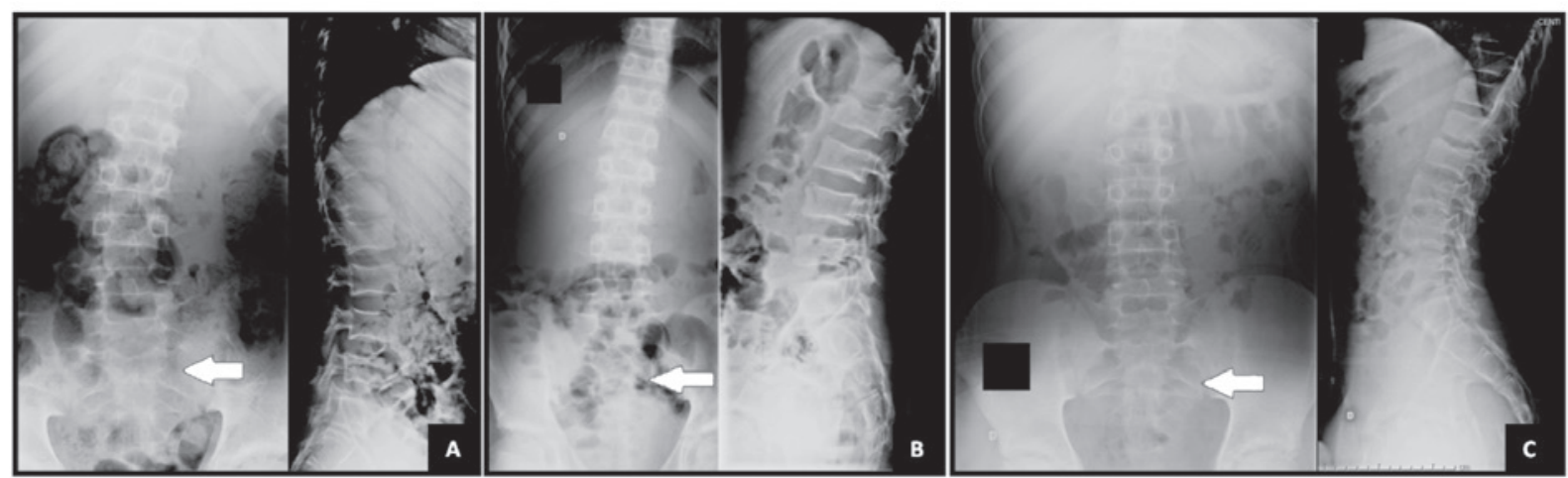

Se realizó una radiografía de columna lumbosacra al momento del ingreso y del alta hospitalaria (1.A y 1.B, respectivamente) sin preparación intestinal adecuada, que limitó su utilidad diagnóstica al evidenciar abundante interposición de asas que podían generar imágenes de confusión en la columna. No se evidenciaron signos inflamatorios en localización anatómica del músculo psoas ni signos de osteomielitis. La radiografía de la columna lumbosacra al momento del alta (1.C) no presentó opacidades ni imágenes en el psoas, sin signos de discitis o lesión ósea en los cuerpos vertebrales.

Las flechas indican el punto de reparo anatómico del músculo psoas izquierdo al ingreso de la pelvis.

FIgURA 2. Resonancia nuclear magnética de la columna dorsal. A) Corte coronal. B) Corte parasagital. C) Corte axial.
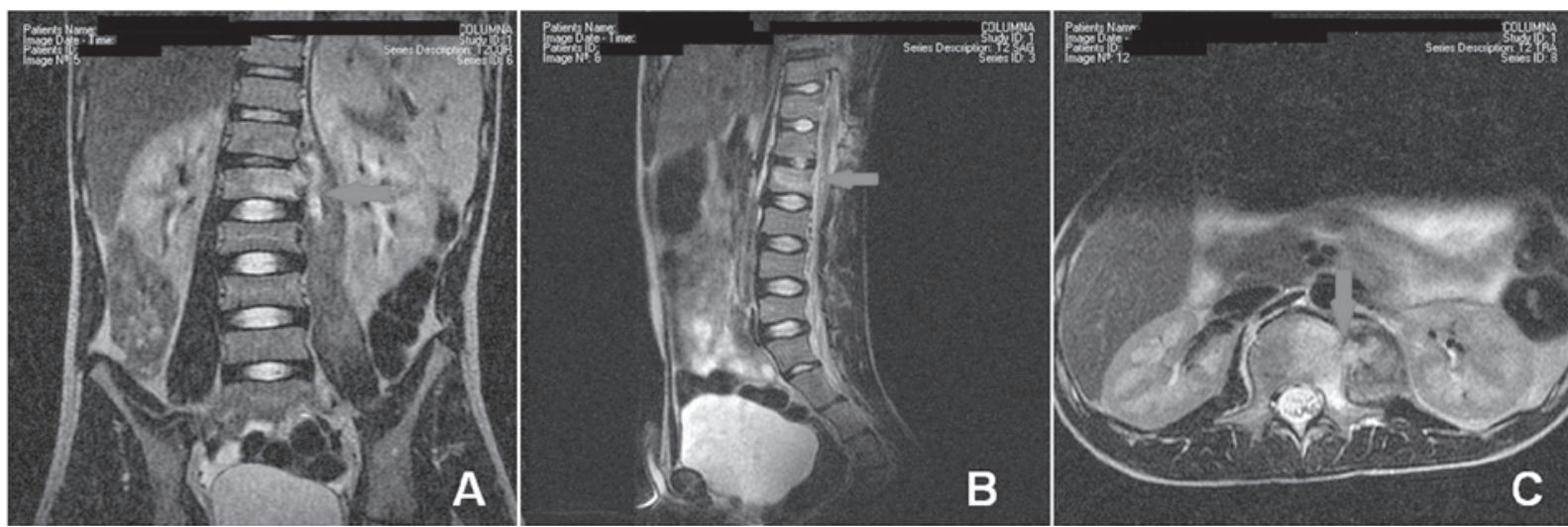

Cortes coronal (2.A), parasagital (2.B) y axial (2.C) de resonancia nuclear magnética de la columna dorsal, en los que se evidenció una lesión hiperintensa en el músculo psoas izquierdo, que se irradiaba y comprometía el cuerpo vertebral de L2.

Las flechas indican la localización del absceso del psoas izquierdo y su infiltración hacia la segunda vértebra lumbar en cada uno de los cortes representados. 
normalización de los parámetros de laboratorio y la negativización de los cultivos. Además, se utilizó la $\mathrm{PCR}^{4}$ como parámetro para decidir el paso al antibiótico oral con clindamicina (30 mg/kg/día) y rifampicina (15 mg/kg/día), que se continuó durante 4 semanas totales, 2 intrahospitalarias y 2 de forma ambulatoria, con resolución completa de los síntomas.

Se efectuó un seguimiento ambulatorio por Consultorio Externo de Traumatología e Infectología Pediátrica al mes y, posteriormente, a los 6 y 12 meses del alta hospitalaria. El paciente se encontró completamente asintomático, con controles radiográficos normales (Figura 1.C) y sin complicaciones ni secuelas derivadas de su patología.

\section{DISCUSIÓN}

A pesar de la baja incidencia del absceso del psoas en la población pediátrica, la gravedad de presentación de este y otros casos reportados en la literatura obliga a considerarlo dentro de los posibles diagnósticos diferenciales en niños con dolor lumbar.

Se puede presentar con espectro clínico muy variable, que va desde síntomas inespecíficos en la región lumbosacra, cadera y muslo hasta la aparición de la tríada típica -en el 30\% de los casos- con fiebre, dolor lumbar y limitación para la marcha o cojera, ${ }^{5}$ por lo que resulta importante hacer el diagnóstico diferencial con artritis séptica de cadera ${ }^{6}$ y espondilodiscitis. ${ }^{7}$

Por lo general, es ocasionado por un único agente. El más comúnmente aislado tanto en abscesos de origen primario como secundarios a osteomielitis es Staphylococcus aureus ${ }^{8}$ y, a finales de 1990, surgió el SAMR como microorganismo asociado con infecciones provenientes de la comunidad. ${ }^{9}$

No existen, en la actualidad, más que algunos reportes de caso que nos orienten sobre la prevalencia real de esta afección en nuestro medio. Todavía es más infrecuente la asociación con osteomielitis ${ }^{10} \mathrm{y}$ bacteriemia por SAMR en niños previamente sanos.

El paciente registró $\mathrm{PCR}$ y eritrosedimentación elevadas, como ocurre en alrededor del $90 \%$ de los casos reportados. ${ }^{11} \mathrm{El}$ control radiográfico no evidenció compromiso óseo, pérdida de la lordosis lumbar ni estrechamiento de los espacios intervertebrales.

Se sabe que algunos hallazgos en la radiografía pueden ser inespecíficos; sin embargo, continúa siendo una herramienta útil, de fácil y rápido acceso en relación con otros estudios más complejos, como la RNM, ${ }^{12}$ que, si bien tiene mejor rendimiento al confirmar la presencia de un absceso intraabdominal y al delimitar afecciones de tipo osteoarticular, requiere autorizaciones, debido a su alto costo, y equipos modernos, que no se encuentran disponibles en todos los niveles de atención. Además, la radiografía permite llevar un seguimiento en el tiempo de las múltiples estructuras relacionadas con la anatomía y patología del psoas, como los discos y cuerpos vertebrales.

A pesar del compromiso grave del paciente con cuadro de bacteriemia por SAMR y osteomielitis de columna vertebral, cabe resaltar que no hubo compromiso del disco intervertebral. Generalmente, el compromiso de las apófisis, pedículos y láminas vertebrales es infrecuente (3\%-12\%) y, cuando ocurre, debe sospecharse la presencia de tuberculosis. Se sabe que es más frecuente en niños debido a los canales vasculares persistentes, mientras que, en los adultos, el disco es avascular y limita la inoculación directa de microorganismos. ${ }^{13}$

Respecto al tratamiento de primera línea, se debe iniciar con antibióticos de amplio espectro que cubran Staphylococcus aureus, como ampicilina/sulbactam, clindamicina, y, de acuerdo con la evolución clínica del paciente y los resultados de cultivos, debe considerarse el tratamiento con vancomicina en los casos en los que se registre infección por SAMR.

Existen diversas posturas respecto a la resolución quirúrgica a través del drenaje del absceso que se encuentran discutidas. En el presente caso, no fue considerado, debido a la evolución clínica favorable tras iniciar el manejo conservador. Por lo general, se prefiere esta opción terapéutica, pues no es invasiva y da buenos resultados en pacientes jóvenes y previamente sanos. El drenaje quirúrgico, generalmente, se guarda como última opción para los casos en los que hay evolución tórpida, el absceso está multiloculado, cuando se comprueba la existencia de un foco infeccioso intraabdominal o se presentan recidivas.

Actualmente, debiera preferirse el drenaje percutáneo guiado por imagen, ya sea ecografía o tomografía, antes que el drenaje quirúrgico, pues se trata de una alternativa segura, menos agresiva, exenta de los riesgos de una cirugía mayor y con resultados que muestran efectividad similar. ${ }^{14}$

Si bien el absceso del psoas es una patología 
infrecuente en pediatría, se debe sospechar ante la presencia de signos clínicos sugestivos, estudiar y tratar de manera rápida, puesto que se ha demostrado que el manejo antibiótico y el drenaje tempranos reducen significativamente su morbimortalidad. ${ }^{15}$

\section{Agradecimientos}

Los autores expresan sus agradecimientos a la doctora Verónica Guedes, asesora principal, por su constante apoyo y valiosas orientaciones.

\section{REFERENCIAS}

1. Shields D, Robinson P, Crowley TP. Iliopsoas abscess - A review and update on the literature. Int J Surg 2012;10(9):4669.

2. Salvatore A, Pavlovsky M, Maxit M, De Wouters L, Valdivia $\mathrm{H}$. El absceso del músculo psoas ilíaco. Medicina (B. Aires) 1996;56(2):126-32.

3. Katara AN, Shah RS, Bhandarkar DS, Unadkat RJ. Retroperitoneoscopic drainage of a psoas abscess. J Pediatr Surg 2004;39(9):e4-5.

4. Pigeon-Oliveros H, Ruano-Aguilar JM, García-Buenrostro N, Palafox-Sánchez R. Absceso del psoas iliaco. Un caso clínico. Acta Méd 2005;3(4):259-63.

5. Medina JF, Vivas VH. Absceso del psoas: revisión de la literatura y estado actual. Rev Colomb Cir 2004;19(3):181-9.
6. Larcamon J, Juanco G, Álvarez L, Pebe FV. Absceso de psoas como complicación de varicela. Arch Argent Pediatr 2010;108(3):86-8

7. Song J, Letts M, Monson R. Differentiation of Psoas Muscle Abscess From Septic Arthritis of the Hip in Children. Clin Orthop Relat Res 2001;(391):258-65.

8. Ricci MA, Rose FB, Meyer KK. Pyogenic psoas abscess: worldwide variations in etiology. World J Surg 1986;10(5):834-43.

9. Kaplan SL. Implications of methicillin-resistant Staphylococcus aureus as a community acquired pathogen in pediatric patients. Infect Dis Clin North Am 2005;19(3):74757.

10. KleinerO,CohenZ,BarkiY,Mares AJ.Unusual presentation of psoas abscess in a child. J Pediatr Surg 2001;36(12):185960.

11. Jordan García I, May Llanas E, Riopedre Saura X, González Pascual E, et al. Absceso de psoas en Pediatría. A propósito de dos casos. An Esp Pediatr 1999;50:172-4.

12. Renwick S, Ritterbusch J. Pyomyositis in children. J Pediatr Orthop 1993;13(6):769-72.

13. Tali ET. Infecciones de la columna vertebral. Euro J Radiology 2004;50(2):120-33.

14. Dinç H, Ahmeto lu A, Baykal S, Sari A, et al. Image guided percutaneous of tuberculous iliopsoas and spondylodiskitic abscesses: midterm results. Radiology 2002;225(2):353-8.

15. Solas Beltrán A, Velasco Sánchez B, Lendínez F, Ramírez Huertas A, Paredes Esteban RM. Tratamiento del absceso de psoas. Aportación de un caso y revisión de la literatura. Cir Pediatr 2002;15(1):41-3. 